\title{
Working
}

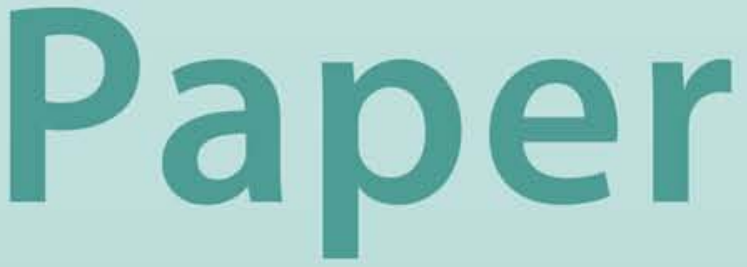


Estimating Poland's Potential Output: A Production Function Approach

Natan Epstein and Corrado Macchiarelli 


\title{
IMF Working Paper
}

\author{
European Department
}

\section{Estimating Poland's Potential Output: A Production Function Approach}

\section{Prepared by Natan Epstein and Corrado Macchiarelli}

Authorized for distribution by James Morsink

January 2010

\begin{abstract}
The paper develops a methodology based on the production-function approach to estimate potential output of the Polish economy. The paper concentrates on obtaining a robust estimate of the labor input by deriving Poland's natural rate of unemployment. The estimated unemployment gap is found to track well pressures on resource constraints. Moreover, the overall results show that, prior to the recent global financial crisis, Poland's output and employment were both growing above potential. The production function is also used to derive medium-term projections of the output gap. According to our methodology, in the aftermath of the global crisis, Poland is not expected to experience a sizable and persistent negative output gap.
\end{abstract}

\section{This Working Paper should not be reported as representing the views of the IMF.} The views expressed in this Working Paper are those of the author(s) and do not necessarily represent those of the IMF or IMF policy. Working Papers describe research in progress by the author(s) and are published to elicit comments and to further debate.

JEL Classification Numbers: C5, E3

Keywords: Production function, potential growth, output gap, NAIRU.

Author's E-Mail Address: nepstein@imf.org; corrado.macchiarelli@unito.it.

\footnotetext{
${ }^{1}$ Corrado Macchiarelli is a Ph.D. student at the University of Torino and was an Intern at the IMF's European Department during the summer of 2009. We thank James Morsink for his useful comments, Alexander Hoffmaister for his early constructive guidance and David Velazquez-Romero and Mariza Arantes for excellent technical assistance. The paper also benefited from comments provided by Andrzej Raczko, Delia Velculescu and participants at a seminar organized by the New Member States Division of the IMF's European Department.
} 


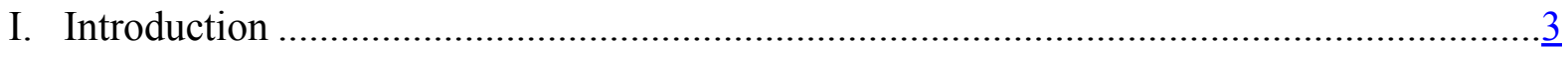

II. The Production Function and Parameter Estimates ....................................................

III. Estimating Potential Inputs ................................................................................

A. First step: Kalman Decomposition of Unemployment .................................. $\frac{7}{7}$

B. Second Step: Economic Identification_-Philips Curve .................................. 9

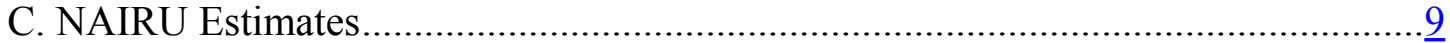

D. Potential Employment..........................................................................

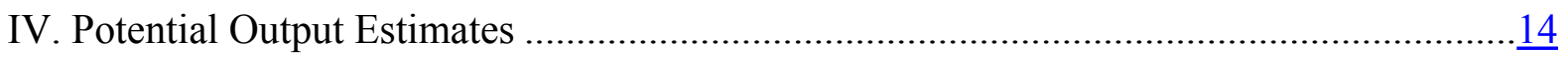

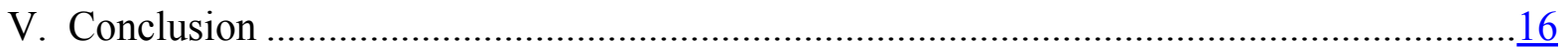

Boxes

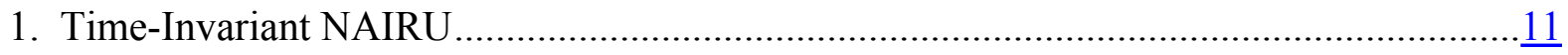

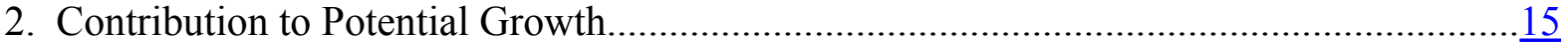

Figures

1. Recursive Estimates of Cobb-Douglas Coefficients .................................................. $\underline{6}$

2. Actual, Equilibrium, and Trend Component of Employment.....................................12

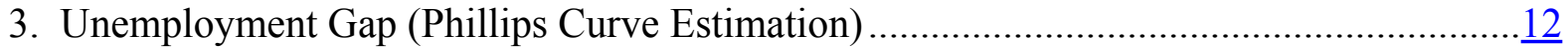

4. Year-on-Year Inflation versus NAIRU Estimates ................................................ $\frac{13}{13}$

5. Observed and Potential labor Market Participation Rate................................................. $\frac{13}{13}$

6. Actual and Equilibrium Employment Level ............................................................. $\frac{13}{14}$

7. Production Function Estimates .................................................................................... 14

Tables

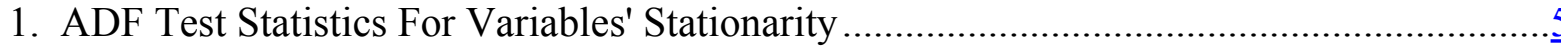

2. Johansen's Cointegration Test................................................................................... $\frac{5}{5}$

3. Static and Dynamic Least Squares Estimation ........................................................... $\frac{5}{8}$

4. Cyclical Component and Phillips Curve Estimates ...................................................

5. Trend and Cyclical Componentes of Unemployment................................................

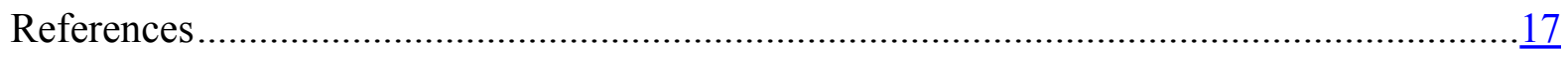

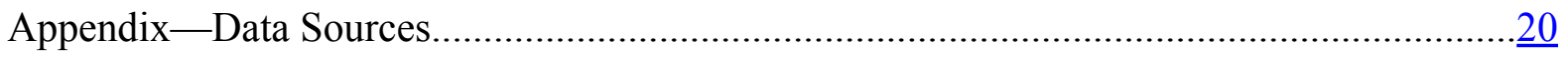




\section{INTRODUCTION}

1. It is well known that estimates of potential productivity levels are useful in evaluating the non-inflationary growth paths of both output and employment. In this regard, purely statistical methods applied to historical levels of output directly, such as the Hodrick-Prescott (HP) filter, tend to misidentify boom and bust periods and the extent to which wide fluctuations in growth are fully driven by economic fundamentals. ${ }^{2}$ The use of an HP filter can be particularly problematic in estimating potential growth in emerging market economies like Poland where output fluctuations can be relatively large, due to their vulnerability to global shocks and to structural changes (such as transition to the market economy, or EU accession). Consequently, a growing consensus has emerged toward 'production function'-based methodologies, which have strong theoretical foundations (see e.g., Cotis et al., 2005, Dupasquier et al, 1997), although new

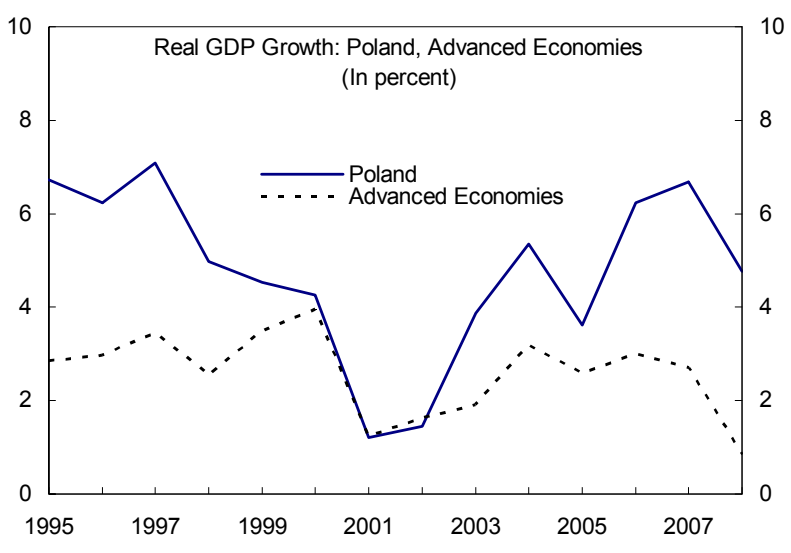
non-parametric methods are also emerging.

2. In this paper, we adopt a standard Cobb-Douglas production function methodology to derive the output gap for Poland over the 1995-2008 period. ${ }^{3}$ To estimate Poland's potential growth, we mainly require that potential output be consistent with the notion of 'full employment.' The estimation entails obtaining Poland's natural rate of unemployment, for which we augment a Kalman decomposition of the unemployment rate with a Philips curve application.

3. We find that, during the boom years preceding the recent financial crisis, Poland was growing above its potential. This is consistent with the observed behavior of inflation and our estimated unemployment gap, and with the view that part of that growth could be characterized as "bubbly." Finally, we employ the new methodology to project potential growth in the medium term. We find that, in the aftermath of the current downturn, Poland is not expected to experience a sizable and persistent negative output gap. Indeed, the crisis spillovers appear to not have been as severe relative to other countries in the region. ${ }^{4}$

4. The structure of the paper is as follows. Section II briefly discusses the production function and presents the parameter estimates for Poland. In section III, we derive the potential levels of the production function inputs, paying particular attention to the

\footnotetext{
${ }^{2}$ A recent analysis of the Irish economy shows that the use of an HP filter to estimate Ireland's output gap would have missed the entire overheating phase during 2005-07 (IMF country Report No. 09/195).

${ }^{3}$ Gradzewicz and Kolasa (2005) adopted a slightly different production function approach to estimate Poland's potential output, covering the 1996-2002 period.

${ }^{4}$ See IMF country Report No. 09/266.
} 
equilibrium employment estimates. Section IV discusses the potential output estimates. Section V concludes.

\section{The Production Function and Parameter Estimates}

5. Following a standard application in the literature, the Polish economy is assumed to be characterized by a Cobb-Douglas production function with constant returns to scale (CRS) technology:

$$
Y_{t}=A_{t} L_{t}^{\alpha} K_{t}^{\beta}
$$

where $Y_{t}$ is output, $L_{t}$ and $K_{t}$ are labor and capital, and $A_{t}$ denotes total factor productivity; and where the output elasticities sum up to one, i.e., $\alpha+\beta=1 .^{5}$

6. The labor input is defined as the number of employees in the economy based on the Polish Labor Force Survey (LFS). The capital stock series is constructed from total investment assuming perpetual inventories, hence:

$$
K_{t}=(1-\delta) K_{t-1}+I_{t}
$$

where capital stock in each period is measured by the previous-period stock (net of depreciation) augmented with new investment flows. Consistent with previous studies, the depreciation rate $\delta$ is assigned the value 0.05 , while an initial benchmark is computed as $K_{1995 Q 1}=I_{1995 Q 1} /(\delta+i)$ with $i$ being the average logarithmic growth rate of investment in the sample period 1995-2008. Unit root tests for GDP, capital and labor suggest that all variables are non stationary (Table 1), while standard Johansen's (1991) cointegration tests suggest the existence of one long-run relationship among the variables (Table 2). ${ }^{6}$ Since a small sample bias remains, dynamic OLS estimates (Stock and Watson, 1993) are also obtained (Table 3 ). ${ }^{7}$ In contrast with the OLS estimates, the sum of the unrestricted DOLS is statistically close to one, hence the CRS assumption. ${ }^{8}$ Indeed, CRS is not rejected at a standard significance level. Moreover, the resulting restricted coefficients are broadly consistent with earlier studies adopting a production-function methodology for the Polish economy (see Gradzewicz and Kolasa, 2005).

\footnotetext{
${ }^{5}$ The estimation uses seasonally adjusted quarterly data for the period 1995Q1-2008Q4. See Appendix I for key data sources. In the estimation all the variables are transformed in natural logarithm.

${ }^{6}$ In light of these results, OLS estimation of the output elasticities in (1) would yield super consistent estimates of the existing cointegrating vector (Stock, 1987).

${ }^{7}$ In small samples, Johansen test has largely been found to be upward biased, rejecting the null hypothesis more often than what asymptotic theory suggests (Zhou, 2000; Johansen, 2002). For estimation of the Polish output gap using a VECM approach, see Gradzewicz and Kolasa (2005).

${ }^{8}$ Since the Polish economy has been subject to structural changes during the sample period, it was worth testing the stability of the unrestricted DOLS estimates. This is done by a set of recursive stability tests. Specifically, a Kalman filter was used to generate a set of least square regressions producing a series of statistics on the behavior of the individual regression parameters. The tests' results suggest a considerable degree of parameter constancy (Figure 1).
} 
Table 1 - ADF test statistics for variables' stationarity

\begin{tabular}{|lcccc|}
\hline \multicolumn{5}{c}{$H_{0}:$ unitary root } \\
Output & $G D P_{t}$ & 0.623 & $\Delta G D P_{t}$ & -4.361 \\
Labour input & $L_{t}$ & $(0.989)$ & & $(0.001)$ \\
& & -0.135 & $\Delta L_{t}$ & -4.056 \\
Capital input & $K_{t}$ & -1.024 & $\Delta K_{t}$ & $(0.002)$ \\
& & $(0.731)$ & & -3.007 \\
& & & &
\end{tabular}

$1 \backslash$ (p-values) in parenthesis.

Table 2 - Johansen's cointegration test

\begin{tabular}{ccccc}
\hline $\begin{array}{c}\text { No. of valid cointegrating } \\
\text { vectors }\end{array}$ & Max Eigenvalue & p-value & Trace & p-value \\
\hline None $^{*}$ & 34.214 & 0.000 & 41.669 & 0.014 \\
1 & 6.816 & 0.5110 & 7.455 & 0.525 \\
2 & 0.638 & 0.4243 & 0.638 & 0.424 \\
\hline
\end{tabular}

$1 \backslash$ Cointegration analysis based on an unrestricted VAR model with 1 lag and no constant term. $2 \backslash\left(^{*}\right)$ denotes rejection at $5 \%$ critical level.

Table 3 - Static and dynamic least squares estimation

\begin{tabular}{lccc}
\hline & OLS & DOLS & DOLS restricted \\
\cline { 2 - 4 } const. & -2.518 & 0.559 & 0.735 \\
$\alpha$ & {$[0.761]$} & {$[0.598]$} & {$[0.027]$} \\
& 0.764 & 0.485 & 0.486 \\
$\beta$ & {$[0.077]$} & {$[0.065]$} & {$[0.007]$} \\
& 0.558 & 0.528 & 0.514 \\
$R^{2}$ & {$[0.011]$} & {$[0.007]$} & {$[0.007]$} \\
$\bar{R}^{2}$ & 0.9788 & 0.9551 & 0.9529 \\
$\sigma^{2}$ & 0.9781 & 0.9541 & 0.9529 \\
$H_{0}: \alpha+\beta=1$ & 0.02877 & 0.01791 & 0.01791 \\
& $F(1,53)=16.878$ & $\chi^{2}(1)=0.0845$ & - \\
\hline
\end{tabular}

1\ In the regression it is used the robust standard errors option (Newey West).

$2 \backslash$ ( $p$-values) and [standard errors] in parenthesis. All coefficients are significant at $1 \%$ critical level.

$3 \backslash$ The number of leads and lags in the DOLS regression is equal to four. 
Figure 1. Poland: Recursive Estimates of Cobb-Douglas Coefficients
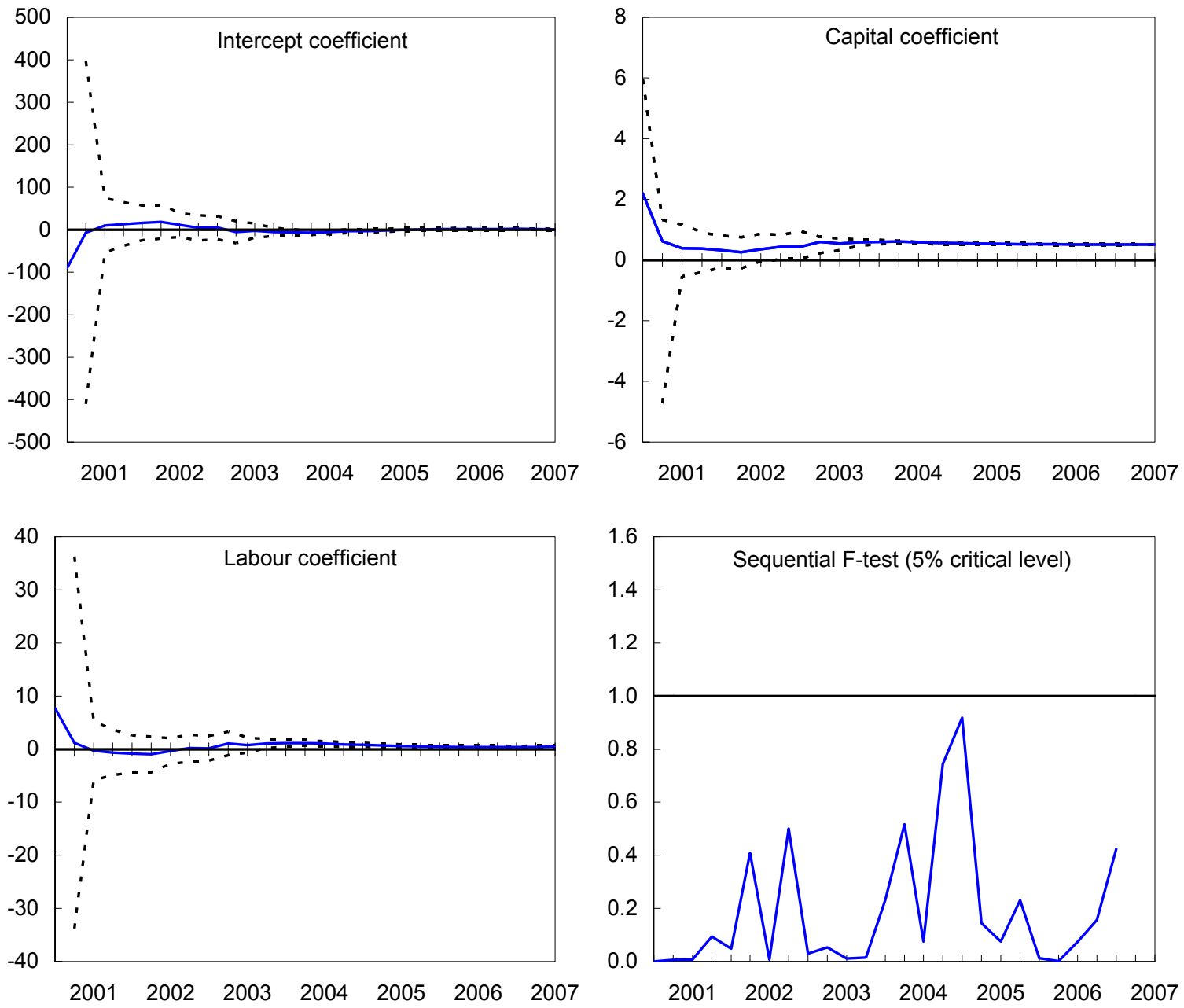

1/ All series for the coefficients are plotted together with upper and lower $( \pm 2)$ confidence bands.

Source: Authors' computations. 


\section{Estimating Potential InPUts}

7. We begin by deriving standard measures for the trend total factor productivity and for the potential utilization of the existing capital stock. The total factor productivity term is obtained as a Solow residual from (1): ${ }^{9}$

$$
A_{t}=\left(\frac{Y_{t}}{L_{t}^{\alpha} K_{t}^{1-\alpha}}\right)
$$

As for the potential utilization of the capital stock, a capacity utilization series is not available. In this regard, and consistent with the literature, we assume the full utilization of the existing stock of capital. Such a simplification mostly relies on the assumption that, given the perpetual inventories rule, the capital stock can be regarded as an indicator for the overall capacity of the economy (Denis et al., 2000) ${ }^{10}$.

8. In order to obtain potential employment, we first derive the non-accelerating inflation rate of unemployment (NAIRU). We estimate the NAIRU in two steps. ${ }^{11}$ First, the unemployment rate is modeled as the sum of a trend and a cyclical component, where the trend component is regarded as a benchmark for the equilibrium unemployment rate and the cyclical component as a reference for the unemployment gap. In the second step, a standard Philips curve relationship is applied to help model the cyclical component.

\section{A. First step: Kalman Decomposition of Unemployment}

9. The unemployment rate is assumed to be described by the sum of a stochastic trend component $\left(\bar{U}_{t}\right)$ and a cyclical component $\left(G_{t}\right)$, as:

$$
U_{t}=\bar{U}_{t}+G_{t}
$$

where the trend component follows a local linear trend model; specifically:

$$
\bar{U}_{t}=\mu_{t}+\bar{U}_{t-1}+\eta_{t}
$$

\footnotetext{
${ }^{9}$ Following Gradzewicz and Kolasa (2005), an approximation for the Polish economy's trend TFP is obtained by smoothing the original series with an HP filter $(\lambda=40)$.

${ }^{10}$ Although standard, such an approach is not without criticism. A proxy for the full utilization of the optimal capital stock should rely on $I_{t}^{*}$ (i.e. the level of investment the economy can produce in the long run). Since it is not clear how the latter can be properly estimated, we follow the standard approach.

11 The equilibrium unemployment rate is expected to generate non-accelerating inflation (Gordon, 1996; Staiger, Stock and Watson, 1996; 2001; Stock and Watson, 1999; Ball, 1996).
} 
where the trend unemployment is described by a random walk plus drift process, and where the drift is allowed to be stochastic, i.e. $\mu_{t}=\mu_{t-1}+\xi_{t}{ }^{12}$ The error term in (5) is assumed to be $\eta_{t} \sim$ i.i.d. and $N\left(0, \sigma_{\eta}^{2}\right)$. When the standard deviation $\sigma_{\eta}=0$ the NAIRU is time-invariant (Box 1), otherwise the NAIRU varies by the amount $\eta_{t}$ in each period. In this regard, we assume a "smoothness prior" $\left(\sigma_{\eta}=0.1\right)$ consistent with Gordon (1996), which allows the long-run unemployment rate to display the desirable property of shifting smoothly. ${ }^{13}$ Following Denis et al. (2002) and Fabiani and Mestre (2004), the cyclical component is modeled as a stationary $\left(\phi_{1}+\phi_{2}<1\right)$ second-order autoregressive process,

$$
G_{t}=\phi_{1} G_{t-1}+\phi_{2} G_{t-2}+\psi_{t}
$$

In this paper we treat both the cyclical and the trend as unobserved components. A Kalman filter is employed to extract these components subject to equations 5 and 6 (Table 4, first column). ${ }^{14}$

Table 4. Cyclical Component and Phillips Curve Estimates

\begin{tabular}{lccc}
\hline Variable & First step results & $\begin{array}{c}\text { Second step results } \\
\text { (Phillips curve } \underline{\text { linear estimation) }}\end{array}$ & $\begin{array}{c}\text { Second step results } \\
\text { (Phillips curve }\end{array}$ \\
\hline constant linear estimation)
\end{tabular}

1\ For column I and III results are obtained using a Kalman smother (Broyden, Fletcher, Goldfarb and Shanno algorithm). $2 \backslash\left({ }^{*}\right)$ denotes significant at $5 \%,\left({ }^{* *}\right)$ significant at $10 \%,\left({ }^{* * *}\right)$ not significant. Otherwise significance is at $1 \%$.

$3 \backslash$ [standard errors] in parenthesis.

${ }^{12}$ Where $\xi_{t} \sim$ i.i.d. and $N\left(0, \sigma_{\xi_{t}}^{2}\right)$.

${ }^{13}$ Here the variance is imposed to be exogenous (known).

${ }^{14}$ See also Hamilton (1994). 


\section{B. Second Step: Economic Identification-Philips Curve}

10. We identify the cyclical component $\left(G_{t}\right)$ according to a Philips curve relationship, i.e.

$$
\Delta \pi_{t+1}=\gamma+\alpha(L) \Delta \pi_{t}+\rho(L) G_{t}+\beta(L) Z_{t}+\varepsilon_{t}
$$

where $\alpha(L), \rho(L)$ and $\beta(L)$ are polynomials in the lag operator of order 2, 0 and 1 , respectively. $\Delta \pi_{t+1}$ is the change in the inflation rate at time $\mathrm{t}+1$, while the exogenous regressor $Z_{t}$ proxies for supply side shocks by including changes in import price inflation.

11. Estimating equation (7) entails a non-linear estimation. For increased precision, the estimation is initialized with an OLS regression where the unemployment gap is first approximated by the cyclical component obtained in the first step. ${ }^{15}$ The cyclical component $\left(G_{t}\right)$ is consequently treated as unobserved and hence re-estimated within equation (7) under the specification in (6). See Table 4 (third column). ${ }^{16}$

\section{NAIRU Estimates}

12. Figure 2 displays the actual unemployment rate together with the results obtained in step one and step two. The equilibrium unemployment derived in the second step is approximated by the predicted unemployment rate consistent with the NAIRU.${ }^{17}$ Henceforth, the paper concentrates on the second step results. Figure 3 reports the unemployment gap (or cyclical component) derived from equation (6) in step two. By definition, the gap is assumed to be the difference between the actual unemployment rate and its equilibrium level. The estimated gap appears to follow the post-reform business cycle in Poland: ${ }^{18}$ it hits a trough at the outset of the 1998 Russia crisis, then rises steadily through the 2001-02 global recession, before declining following EU membership. The gap appears to hit a bottom again during the current downturn, driven by the global financial crisis. In Table 5, the observed unemployment rate series is reported together with the results obtained above. A standard HP filter of the unemployment rate is also reported as an additional reference.

\footnotetext{
${ }^{15}$ Namely the change in inflation at $\mathrm{t}+1$ is regressed on the unemployment gap, on the lagged changes in inflation (with $\alpha(L)=\alpha_{0}-\alpha_{1} L-\alpha_{2} L^{2}$ ), on $Z_{t}$ (with $\beta(L)=\beta_{0}-\beta_{1} L$ ) and on a shift dummy for the years after 2006. The dummy variable is included in order to account for changes in inflation. In particular, by imposing a change in the mean for inflation after 2006 the series is divided into (1995-2005), i.e. when inflation was mostly trending lower; and (2006-2008), when inflation trended higher. The results for the OLS regression are reported in Table 4 (second column).

${ }^{16}$ Consistent with other studies (Denis et al., 2002), the coefficients in the non linear Phillips curve equation always have the correct sign but they are not all significant at a conventional significance level.

${ }^{17}$ The smoother is initialized by imposing the NAIRU to assume the initial values of the HP filtered unemployment rate. For the cyclical component, we imposed a zero sample mean.

${ }^{18}$ During the transition period, Poland adopted comprehensive economic and political reforms in the attempt to rapidly move toward a market economy (Kacanovich et al., 2005).
} 


\begin{tabular}{|c|c|c|c|c|c|c|c|c|c|c|c|c|c|c|}
\hline & 1995 & 1996 & 1997 & 1998 & 1999 & 2000 & 2001 & 2002 & 2003 & 2004 & 2005 & 2006 & 2007 & 2008 \\
\hline Observed unemployment rate & 13.4 & 12.4 & 11.2 & 10.6 & 13.8 & 16.1 & 18.3 & 19.9 & 19.6 & 18.9 & 17.7 & 13.8 & 9.6 & 7.1 \\
\hline \multicolumn{15}{|l|}{ Trend component } \\
\hline Step one (Kalman decomposition) & 12.1 & 12.1 & 12.3 & 12.6 & 13.4 & 14.2 & 14.8 & 15.2 & 15.1 & 14.7 & 14.0 & 12.7 & 11.3 & 10.0 \\
\hline Step two (Phillips curve) & 12.5 & 12.5 & 12.8 & 13.3 & 14.7 & 15.9 & 17.0 & 17.7 & 17.6 & 16.9 & 15.7 & 13.5 & 11.1 & 8.8 \\
\hline Hodrick-Prescott & 12.0 & 12.0 & 12.3 & 13.1 & 14.5 & 16.1 & 17.6 & 18.7 & 18.9 & 18.1 & 16.4 & 13.9 & 11.0 & 7.9 \\
\hline \multicolumn{15}{|l|}{ Cyclical component } \\
\hline Step one (Kalman decomposition) & 1.2 & 0.2 & -1.0 & -2.0 & 0.4 & 1.9 & 3.5 & 4.8 & 4.5 & 4.2 & 3.8 & 1.1 & -1.7 & -2.9 \\
\hline Step two (Phillips curve) & 0.8 & 0.2 & -1.2 & -2.7 & -1.6 & 0.2 & 0.9 & 2.0 & 2.1 & 2.1 & 2.1 & 0.9 & -1.2 & -1.8 \\
\hline Hodrick-Prescott & 1.4 & 0.3 & -1.1 & -2.5 & -0.7 & 0.0 & 0.6 & 1.3 & 0.8 & 0.9 & 1.3 & -0.1 & -1.4 & -0.8 \\
\hline
\end{tabular}

$1 \backslash$ Reported values based on annual averages.

2) The smoothing parameter for the HP filter is $\lambda=1600$

13. The empirical relationship between the estimated equilibrium unemployment rate and the rate of inflation is well documented. For example, Ball $(1996 ; 2009)$ finds a strong empirical relationship between the natural rate of unemployment and disinflation, i.e., countries having experienced large disinflation have encountered a corresponding increase in their natural rate of unemployment. ${ }^{19}$ Poland is no exception to this rule (Figure 4).

\section{Potential Employment}

14. Given the long-run unemployment rate estimates, Polish potential employment level can now be computed as:

$$
L_{t}^{*}=\operatorname{active}_{t} P R_{t}^{*}\left(1-N A I R U_{t}\right)
$$

where active $_{t}$ is the working age population and $P R_{t}^{*}$ is the trend (or equilibrium) participation rate. The main advantage of using equation (8) is that it results in a potential employment series that is relatively smooth and takes account of changes in the working age population, the trend participation rate, and the structural unemployment rate (NAIRU). A proxy for the equilibrium participation rate is obtained by regressing the actual activity rate on a constant, the unemployment rate and a time trend. The resulting fitted values have been used as a measure for the potential participation rate (Figure 5) ${ }^{20}$. Indeed, the overall increase in unemployment during the period 1998-2004 is consistent with a downward trend in the participation rate ${ }^{21}$. Poland's actual and estimated potential employment are depicted in Figure 6.

\footnotetext{
${ }^{19}$ In the literature this is largely explained by hysteresis theories. This might not necessarily be true for a converging economy.

20 The outcome of the OLS regression is not reported. The unemployment rate enters with the expected negative $\operatorname{sign}(-0.049)$.

${ }^{21}$ The decline in Poland's participation rate over the period was seen as a byproduct of the large net migration trends to Western Europe that began in the late 80s (See Korys, 2003).
} 


\section{Box 1 - Time-Invariant NAIRU}

The standard NAIRU model is based on an expectational augmented Phillips Curve relation (Greene, 2003):

$$
\pi_{t+1}-\pi_{t+1}^{e}=\rho(U-\bar{U})_{t}+\beta Z_{t}+v_{t}
$$

where $\pi_{t+1}^{e}$ is the expected inflation rate for period $t+1$. As in Staiger, Stock and Watson (1991), a random walk model for inflationary expectations is applied, i.e. $\pi_{t+1}^{e}=\pi_{t}$ so that $\pi_{t+1}-\pi_{t}=\Delta \pi_{t+1}$.

Since equation (a) does not accommodate serial correlation, it is conventionally estimated in an autoregressive specification, as:

(b)

$$
\Delta \pi_{t+1}=\alpha(L) \Delta \pi_{t}+\rho(L)(U-\bar{U})_{t}+\beta(L) Z_{t}+\varepsilon_{t},
$$

where $\alpha(L), \rho(L)$ and $\beta(L)$ are lag polynomials and $\varepsilon_{t}$ is a non-serially correlated error term.

If $\bar{U}_{t}$ is unobserved, the estimation of equation (b) is non linear. Alternatively, by assuming the equilibrium rate of unemployment to be time invariant (the so called "textbook" NAIRU), equation (b) can be reformulated in such a way to be conveniently estimated by OLS. Assuming $\bar{U}_{t}$ to be constant, equation (b) can be reformulated as:

(c)

$$
\Delta \pi_{t+1}=\gamma+\alpha(L) \Delta \pi_{t}+\rho(L) U_{t}+\beta(L) Z_{t}+\varepsilon_{t}
$$

with $\gamma=\rho(L) \bar{U}=\bar{U} \sum_{i=1} \rho_{i}$. It is straightforward to derive $\bar{U}=-\gamma / \sum_{i=1} \rho_{i}{ }^{22}$

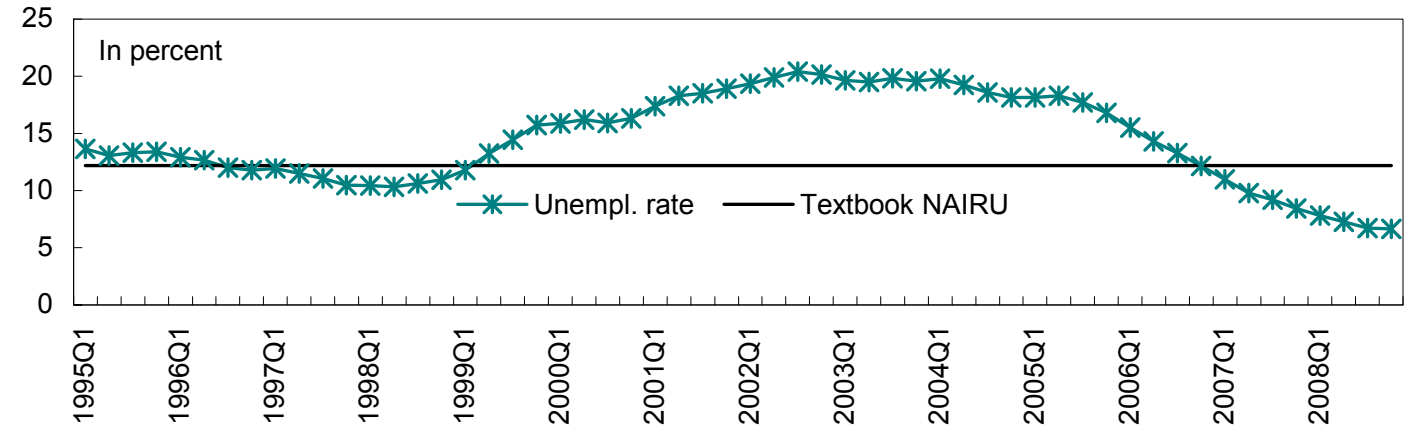

Source: IMF World Economic Outlook and authors' computations.

${ }^{22}$ Estimates are computed by using no lags for unemployment, 12 lags respectively for both inflation and changes in the commodity price index. The regression includes a dummy accounting for the changes in inflation on the overall sample period. 
Figure 2. Poland: Actual, Equilibrium, and Trend Component of Unemployment

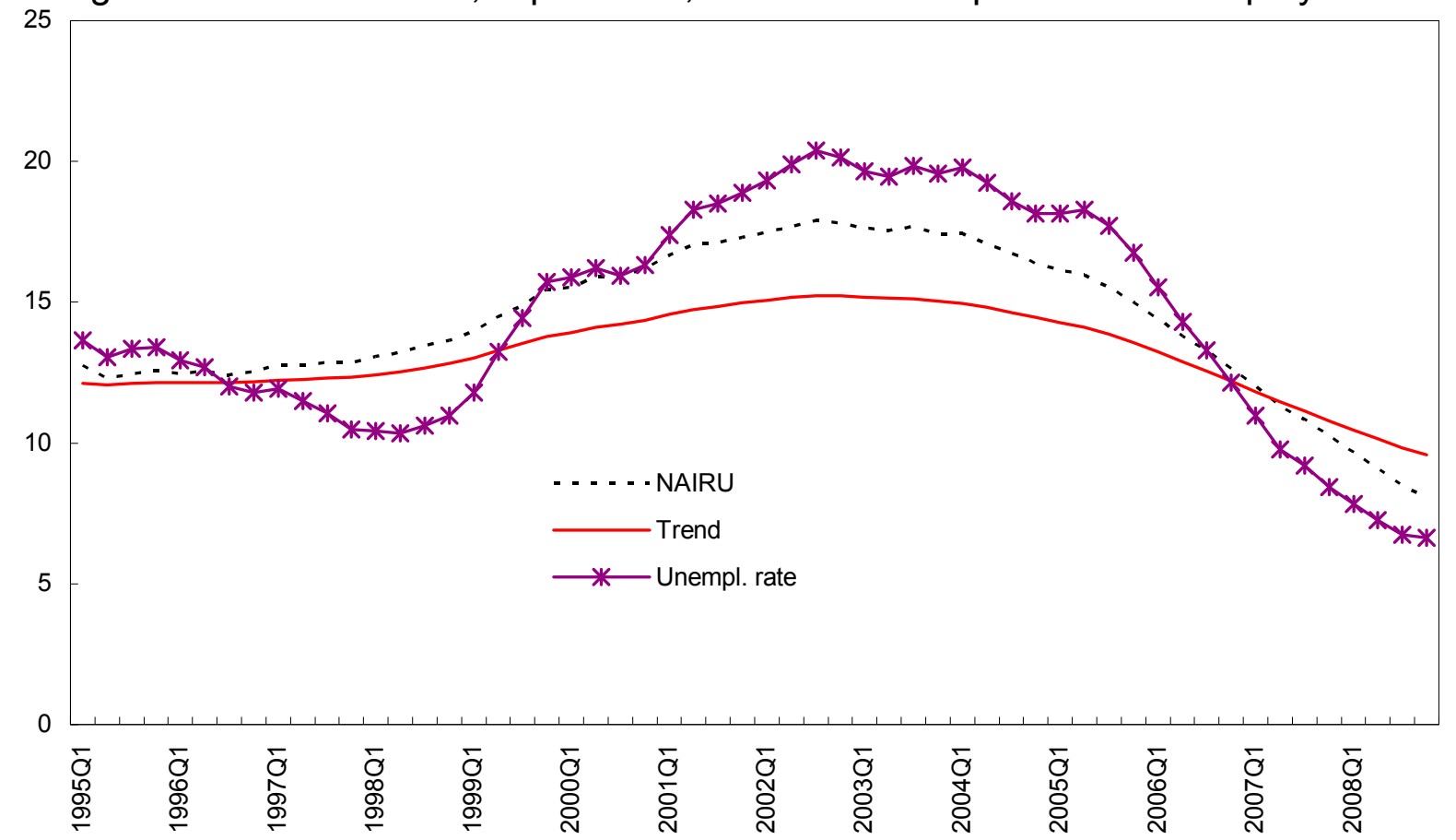

Figure 3. Poland: Unemployment Gap (Phillips Curve Estimation) 1/

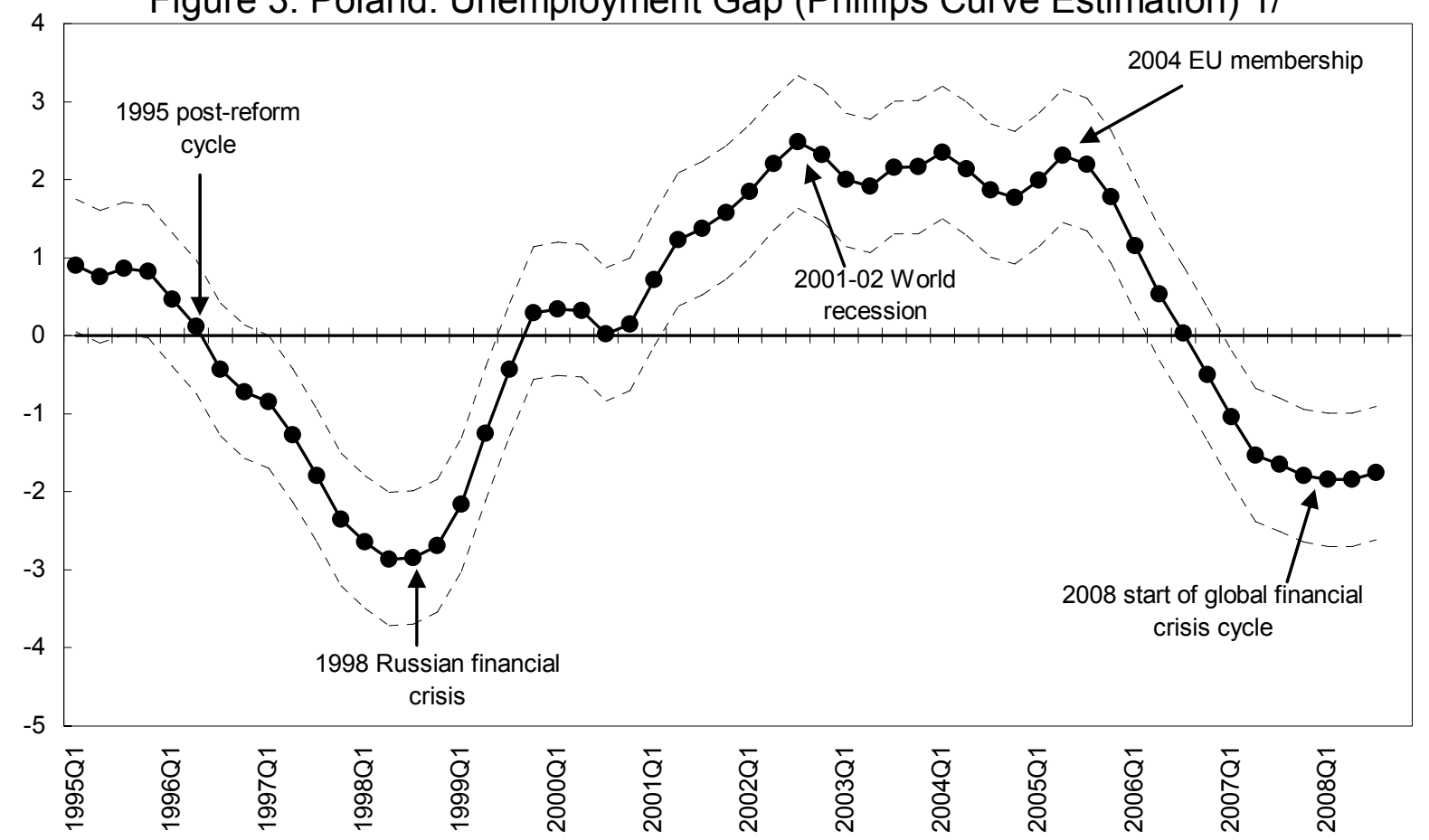

Source: WEO and authors' computations.

1 / The unemployment gap is plotted together with upper and lower $( \pm 2)$ confidence bands. 
Figure 4. Poland: Year-on-Year Inflation versus NAIRU Estimates

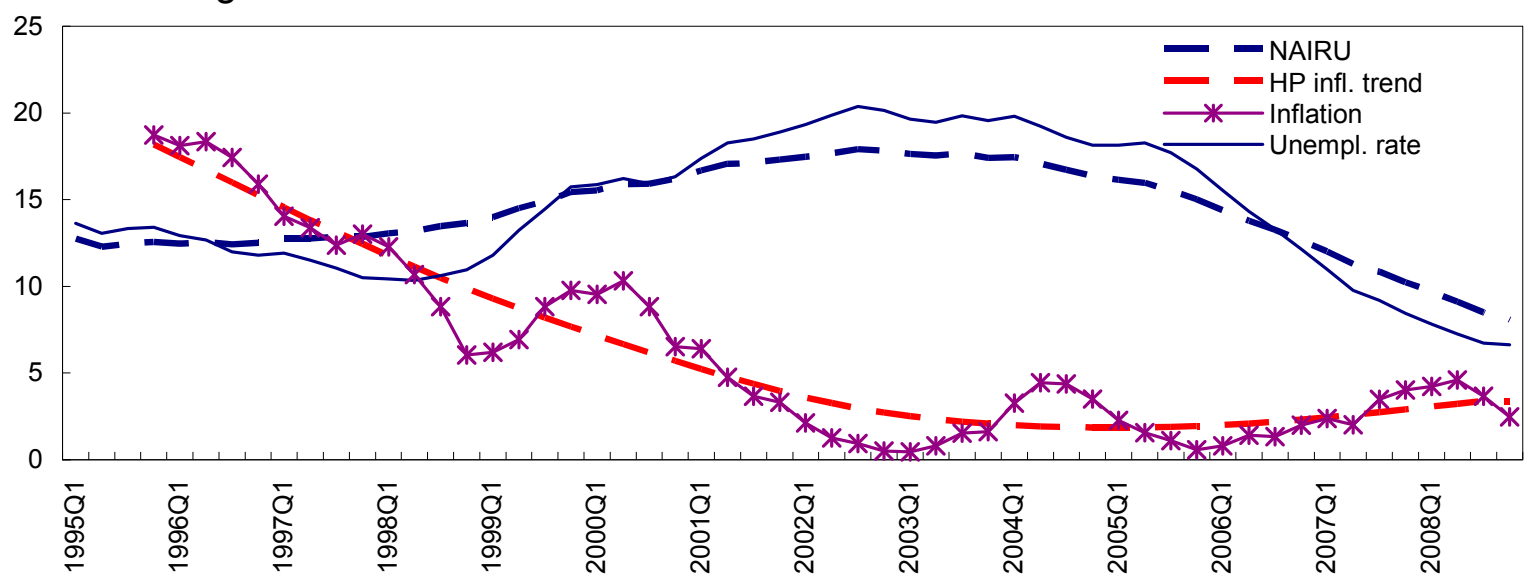

Figure 5. Poland: Observed and Potential Labor Market Participation Rate

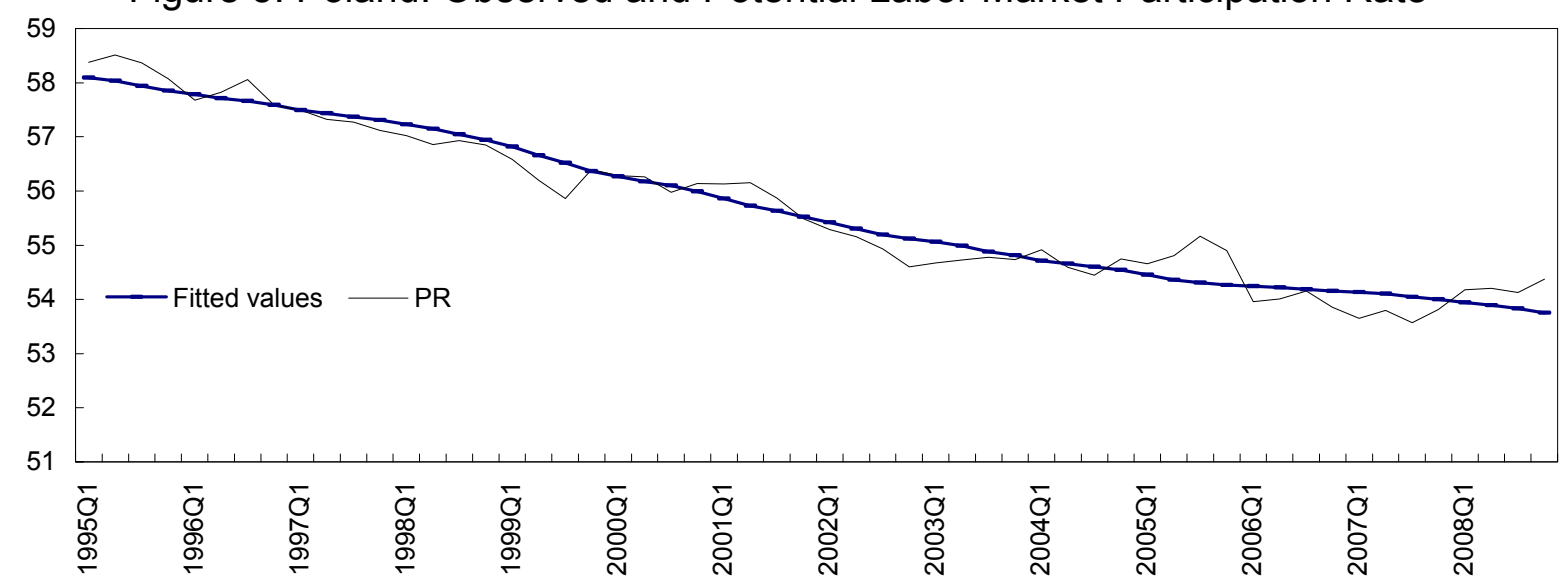

Figure 6. Poland: Actual and Equilibrium Employment Level

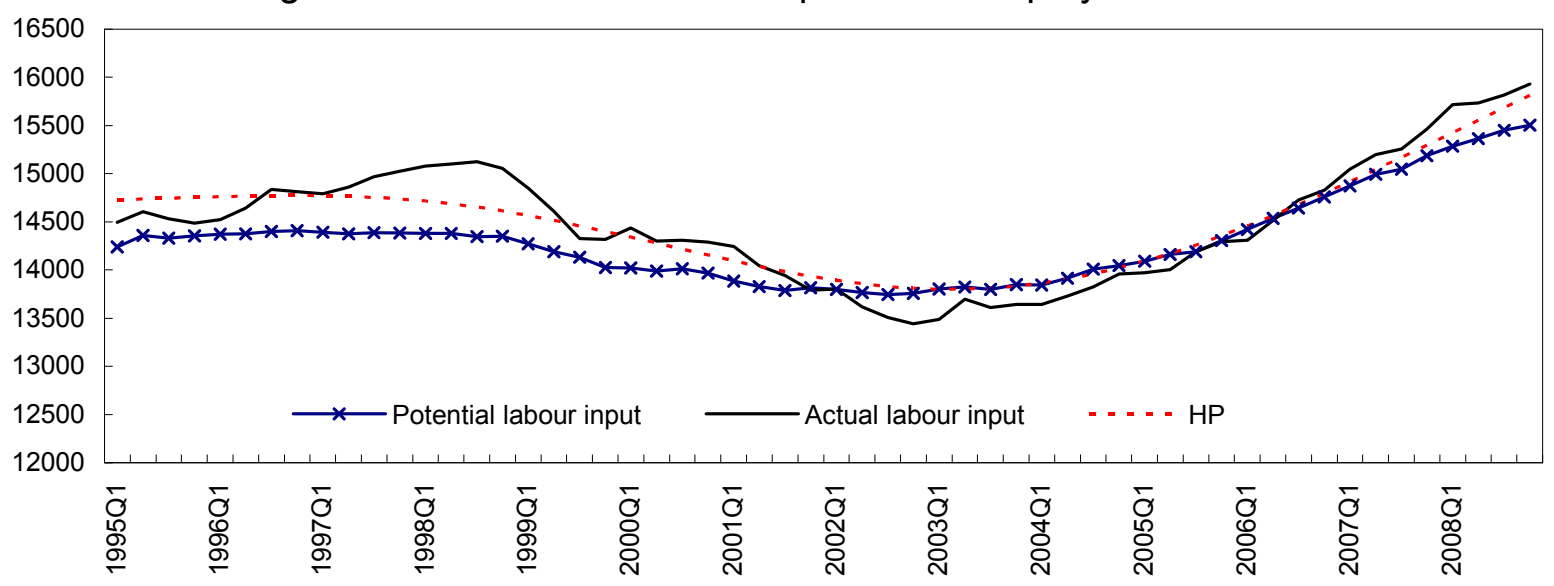

Source: IMF World Economic Outlook and authors' computations. 


\section{Potential Output Estimates}

15. Given the aforementioned trend TFP and potential labor, potential output can be estimated as $Y_{t}=A_{t}^{*} L_{t}^{* \alpha} K_{t}^{1-\alpha}$. The key results are depicted in Figure 7. During the boom years preceding the recent financial crisis, Poland was growing above its potential, with an output gap of 2 percent by early 2008. This is also confirmed with an HP filter series. However, while the HP-based output gap peaked earlier and turned negative by end-2008, our new production-function output-gap series exhibits a more gradual reversal, indicating the Polish economy was at a level above potential even as late as the fourth quarter of 2008. This latter observation is also consistent with the behavior of employment relative to its potential. While the annual growth rate of potential employment was slowing down from about 3 percent in early-2008 to 2 percent by the fourth quarter, the growth rate of actual employment remained above 3 percent throughout the year. Thus, to some degree, these results provide evidence that Poland's rapid output and employment growth pre-crisis was unsustainable.

Figure 7. Poland: Production Function Estimates 1/
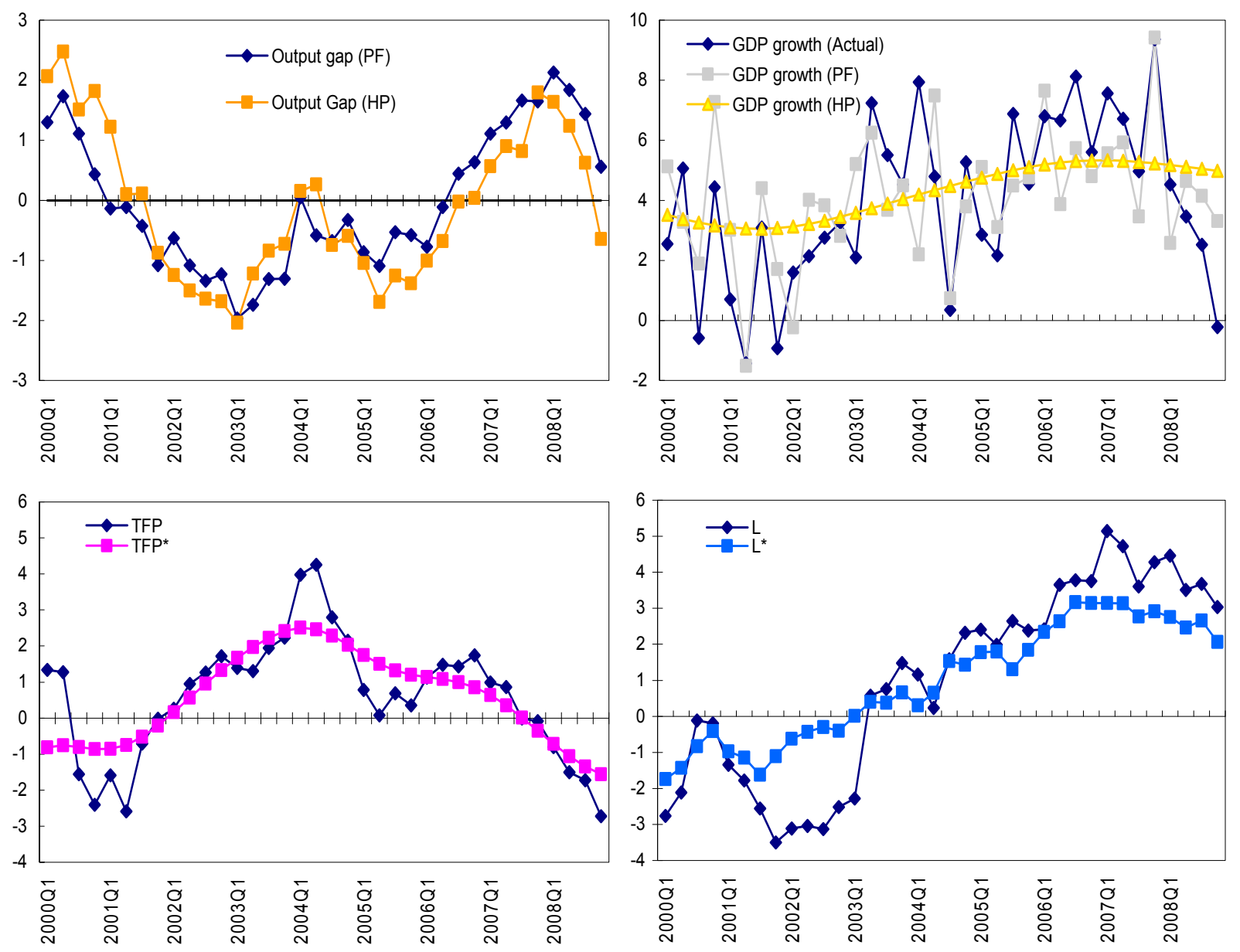

1/ Output gap is computed as $\left(Y_{t}-Y_{t}^{*}\right) / Y_{t}^{*}$, where * denotes potential. GDP growth rates are in q/q annualized, while employment and TFP growth rates are in percent $y / y$.

Source: WEO and authors' computations. 
16. Further evidence of the unsustainability of the growth pattern before the crisis can be uncovered by examining the changes in the contributions of underlying components to Poland's potential growth in recent years (Box 2). We find that following the 2001-02 recession, the contribution of factor productivity growth was rising steadily through 2004 . It remained positive until 2007, but then turned negative through late-2008-largely coinciding with the trend-reversal in potential output growth. At the same time, the contribution of capital was steadily increasing, but it was insufficient to prevent the growth in potential output from declining throughout 2008. Indeed, this suggests that the rapid investment-led output growth in 2006-07 was unsustainable and driven less by fundamentals than one might have considered at the time.

\section{Box 2 - Contribution to Potential Growth}

The production function framework allows us to estimate the contribution of each factor of production to potential GDP growth. Changes in these contributions can be assessed as a signal for structural changes in the Polish economy. Below, labor and capital contributions are plotted, accounting for their respective factor shares. Labor contribution has risen in recent years (largely reflecting a decrease in the NAIRU from 2004), while the contribution of capital has steadily increased, and the contribution of factor productivity decreased. Further insight can be obtained from a similar decomposition of the potential labor series. It shows that most of the increase in the potential labor force can be attributed to a corresponding decline in the NAIRU, with the rate of growth in Poland's active population holding roughly constant since 2004. Concurrently, the participation rate has been decreasing at a constant rate with a negligible effect on the growth of the equilibrium employment rate.
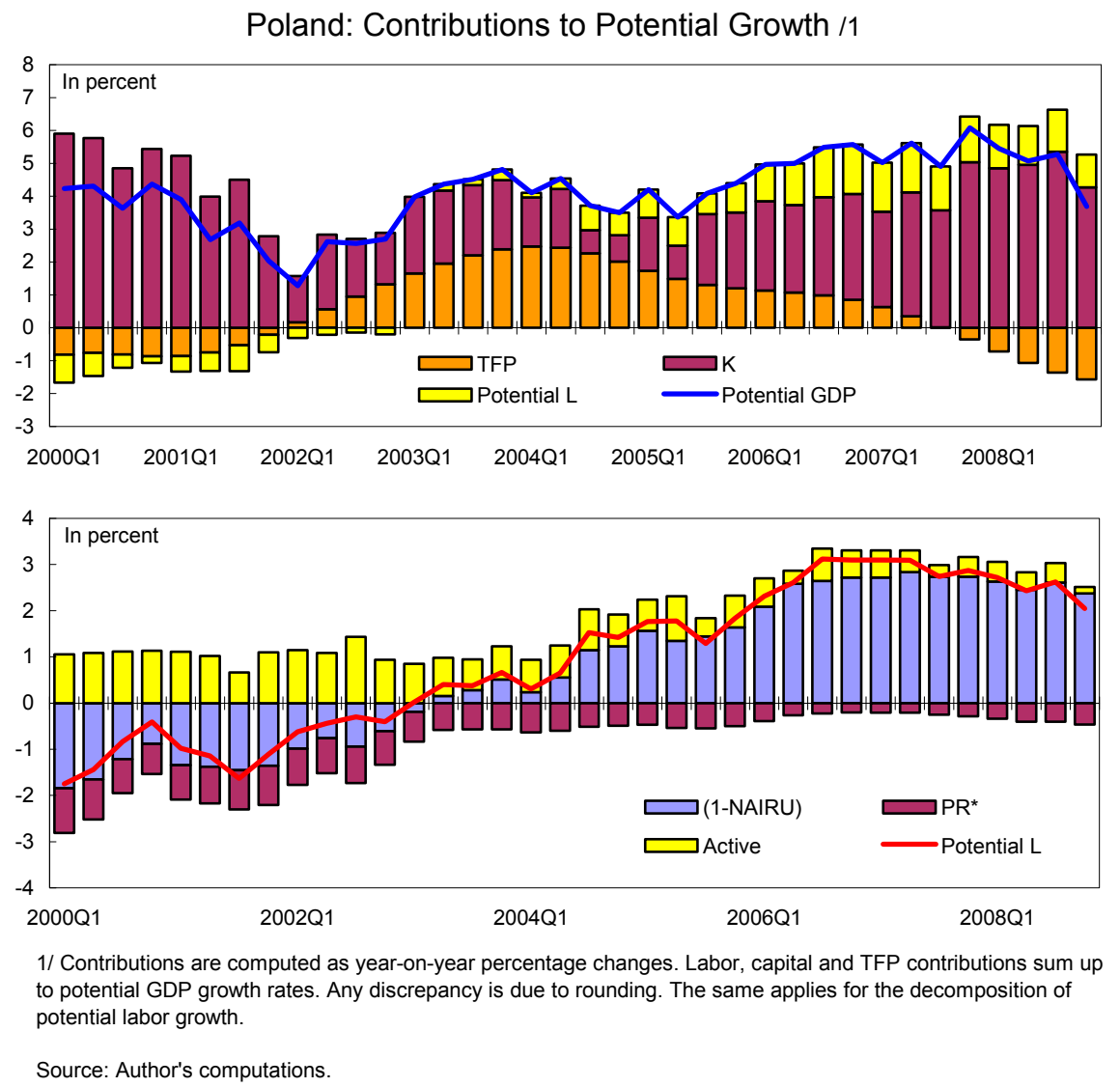
17. Finally, for the purpose of forecasting Poland's potential growth, we extend the estimation through the fourth quarter of $2010 .{ }^{23} \mathrm{We}$ find that our measure of the output gap turned negative in the first quarter of 2009 and is expected to remain negative throughout 2010. However, the output gap is projected to bottom out at just around minus 1 percent, during the second quarter of 2010 , vs. minus 2 percent in the 2001-02 downturn. The output gap is expected to close in 2011. This contrasts somewhat with the experience of other European countries, many of whom currently have negative output gaps

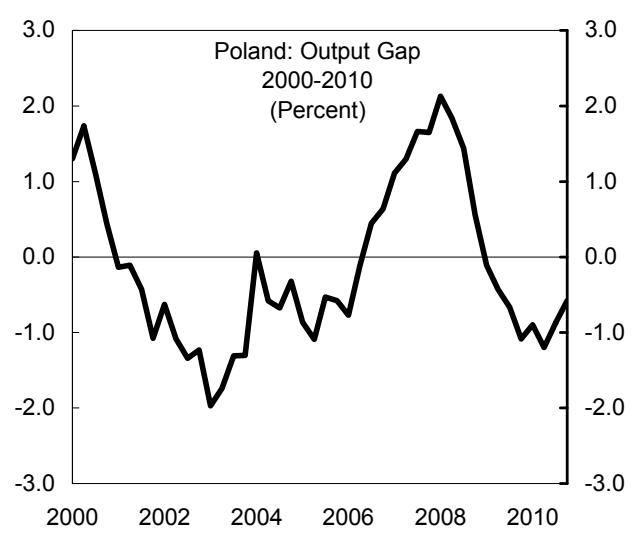
that are larger and expected to persist for a number of years.

\section{Conclusion}

18. In this paper, we adopt a standard Cobb-Douglas production function to estimate Poland's potential growth. Given data limitations on the capital stock, the paper focuses on attaining a robust estimate of the labor input. In order to obtain the measure for potential employment, we derive a NAIRU in two steps. The unemployment rate is first assumed to be described by the sum of a trend and a cyclical component. The trend component is regarded as a benchmark for the equilibrium unemployment rate, while the cyclical component as a reference for the unemployment gap. In the second step, a standard Philips curve relationship is applied to help model the cyclical component.

19. We find that, compared with the HP filter approach, the production-function methodology helps to identify better the most recent boom-bust turning points. The results show that during the pre-crisis period, Poland's output was growing above its potential. This is also confirmed by the behavior of employment relative to its equilibrium measure.

Moreover, by disaggregating the contributions to potential growth, we find that the pre-crisis decline in TFP coincided with the deceleration in the growth of potential output. At the same time, the contribution of capital was steadily rising, suggesting that the rapid investment-led output expansion during that period was unsustainable. Finally, we find that in the aftermath of the global crisis, Poland is not expected to experience a sizable and persistent negative output gap.

\footnotetext{
${ }^{23}$ In line with the horizon for which quarterly projections were available at the time. For consistency, the parameter estimates from the 1995:I-2008:IV sample are left unchanged, while the forward-looking NAIRU is modeled consistent with a relatively stable inflation outlook. Hence, following Denis et al. (2002), $N A I_{t+1}=N A U_{t} U_{t}+0.5\left(N A \operatorname{IRU}_{t}-N A \operatorname{IR} U_{t-1}\right)$.
} 


\section{REFERENCES}

Apel M., Jansson P. (1998), "A Theory-Consistent System Approach for Estimating Potential Output and the NAIRU," Working Paper Series 74, Sveriges Riksbank (Central Bank of Sweden).

Ball L. (1996), "Disinflation and the NAIRU”, NBER Working Paper W5520.

Carabenciov I et al. (2008), “A Small Quarterly Projection Model of the US Economy”, IMF Working Paper 278.

Coen R.M., Hickman B.G., "An econometric model of potential output, productivity growth and resource utilization”, Journal of Macroeconomics 28, pp. 645-664.

Cotis J.P , J. Elmeskov and A. Mourougane (2005), "Estimates of potential output: Benefit and pitfalls from a policy perspective", in L. Rechling (ed), Euro area business cycle: stylized facts and measurement issues, CEPR London.

Denis et al. (2002), "Production Function Approach to calculating Potential Growth and Output Gaps. Estimates for the EU member states and the US", European Commission Economic Paper 176.

Dupasquier et al. (1997), “A comparison of Alternative Methodologies for Estimating Potential Output and the Output Gap", Bank of Canada, Working Paper 97-5.

Fabiani S., Mestre R.(2004), “A system approach for measuring the euro area NAIRU”, Empirical Economics, no. 29, pp. 311-41.

Furceri D., Mourougane A. (2009), “The Effect of Financial Crises on Potential Output: New Empirical Evidence from OECD Countries”, OECD Economic Department, Working Paper no. 699.

Giorno et al. (1995), "Estimating Potential Output, Output Gaps and Structural Budget Balances", OECD, Economics Department, Working Paper 152.

Gordon R.J. (1996), “The time-varying NAIRU and its Implications for Economic Policy”, NBER Working Paper 5735.

Gordon R.J. (1998), "Foundation of the Goldilocks Economy: Supply Shocks and the Time Varying NAIRU”, Brooking Paper on Economic Activity, no. 2, pp.297-346.

Gradzewicz M., Kolasa M. (2005), "Estimating the output gap in the Polish economy: VECM approach”, IFC Bulletin no. 20.

Greene W.H., (2002), “Econometric Analysis”, New York University, chpt 19. 
Hamilton, J.D, (1994), "Time Series Analysis”, Princeton, Princeton University Press, chpts 5 and 13.

Hajkova D., Hurnik J. (2007), "Cobb-Douglas Production Function: The Case of a Converging Economy", Czech Journal of Economics and Finance, 57 no. 9-10.

Hodrick R., Prescott E.C. (1997), "Postwar U.S. Business Cycles: An Empirical Investigation," Journal of Money, Credit, and Banking, vol. 29, pp. 1-16.

IMF country Report No. 09/195

IMF Country Report No. 09/266.

Johansen S. (1991), "Estimation and Hypothesis Testing of Cointegration Vectors in Gaussian Vector Autoregressive Models”, Econometrica 59, 1551-1580.

Johansen S. (2002), “A small sample correction for tests of hypotheses on the cointegrating vectors", Journal of Econometrics, no. 111, pp.195-221.

Juselius K. (2006), “The Cointegrated VAR Model, Methodology and Applications”, Oxford University Press, New York.

Kacanovich J. et al. (2005), “Understanding Reforms: The Case of Poland”, Centre for Social and Economic Research, Case Report, no.59.

King,R., Plosser,C., Stock,J., Watson,M. (1991), "Stochastic trends and economic fluctuations", American Economic Review, no. 81, pp. 819-40

Korys I. (2003), "Migration trends in selected EU applicants countries: Poland", CEFMR Working Paper, 5/2003.

Polish Ministry of Economy, Analyses and Forecasting Dept. (2009), “A Study of Poland Economic Performance in the year 2008".

Polish Ministry of Economy, "Poland 2008 - Report Economy".

Shapiro M.D., Watson M.W. (1988), “Sources of Business Cycle Fluctuations”, Cowles Foundation Discussion Paper 870.

Staiger D., Stock J.H., Watson M.W. (1991), "Prices, Wages and the US Nairu in the 1990s", NBER Working Paper 8320.

Staiger D., Stock J.H., Watson M.W. (1996), "How Precise are the estimates of the Natural Rate of Unemployment?”, NBER Working Paper 5477. 
Staiger D., Stock J.H., Watson M.W. (1997), “The NAIRU, Unemployment, and Monetary Policy", Journal of Economic Perspective, no. 11, pp. 33-49.

Stock, J.H. (1987), “Asymptotic properties of least squares estimators of co-integrating vectors", Econometrica, no. 55, pp. 1035-1066.

Stock, J.H., Watson M. (1993), “A simple estimator of cointegrating vectors in higher Order integrated systems”, Econometrica, no. 61, pp. 783-820.

Stock J.H., Watson M.W. (1999), “Forecasting Inflation, NBER Working Paper 7023.

Stock J.H., Watson M.W. (2002), "Has the Business Cycle Changed and Why", NBER Working Paper 9127.

Stock J.H., Watson M.W. (2008), "Phillips Curve Inflation Forecasts", NBER Working Paper No. 14322.

Watson M.W. (1986), "Univariate Detrending with Stochastic Trends”, Journal of Monetary Economics, Vol. 18, pp. 49-75.

Willman A. (2002), "Euro Area Production Function and Potential Output, A Supply Side System Approach”, European Central Bank Working Paper 153.

Zhou S. (2000), “Testing Structural Hypotheses on Cointegration Relations with Small Samples”, Economic Inquiry (Oxford University Press), no. 38, pp. 629-40. 


\section{APPENDIX-Data SourCES}

\begin{tabular}{|c|c|c|}
\hline Series & Description & Source \\
\hline$Y_{t}$ & $\begin{array}{l}\text { GDP in constant } 2000 \text { prices, } \\
\text { seasonally adjusted series (zloty } \\
\text { millions). }\end{array}$ & IMF, World Economic Outlook. \\
\hline$L_{t}$ & $\begin{array}{l}\text { Employed people (thousands), } \\
\text { Labour Force Survey, seasonally } \\
\text { adjusted series. }\end{array}$ & IMF, World Economic Outlook. \\
\hline$K_{t}$ & $\begin{array}{l}\text { Capital stock, total economy, volume } \\
\text { (million), seasonally adjusted series. }\end{array}$ & Authors' computations. \\
\hline$I_{t}$ & $\begin{array}{l}\text { Total Investment current prices } \\
\text { (zloty million), not seasonally } \\
\text { adjusted series. }\end{array}$ & IMF, World Economic Outlook. \\
\hline$d^{G D P}$ & GDP deflator. & IMF, World Economic Outlook. \\
\hline$L F_{t}$ & $\begin{array}{l}\text { Total labour force, Labour Force } \\
\text { Survey. }\end{array}$ & IMF, Macroeconomic Labour Data. \\
\hline active $_{t}$ & $\begin{array}{l}\text { Working age population (thousands), } \\
\text { seasonally adjusted series. }\end{array}$ & Labour Force Survey. \\
\hline$P R_{t}$ & $\begin{array}{l}\text { Participation rate (percent of total } \\
\text { labour force population). }\end{array}$ & IMF, Macroeconomic Labour Data. \\
\hline$U N_{t}$ & $\begin{array}{l}\text { Unemployed population, Labour } \\
\text { Force Survey, seasonally adjusted } \\
\text { series. }\end{array}$ & IMF, Macroeconomic Labour Data. \\
\hline$U_{t}$ & $\begin{array}{l}\text { Unemployment rate (percent of total } \\
\text { labour force population). }\end{array}$ & IMF, Macroeconomic Labour Data. \\
\hline$c p i_{t}$ & Consumer price index. & IMF, World Economic Outlook. \\
\hline Pcom $_{t}$ & Commodity price index. & IMF, World Economic Outlook. \\
\hline
\end{tabular}

